\title{
A multistorey transit shed and warehouse for the Port of London Authority
}

\author{
F. G. PEAKE \& R. A. SHEWRING
}

Mr J. H. Gabony, Docks Manager, India and Millwall Docks, Port of London Authority

The more controversial criticism is the provision of four overhead electric cranes. This was obviously much too generous, even if the rail connexion had been left underneath. We think that one would have been sufficient-this is a criticism not of the engineers, but of the planners. These cranes are not used very much except for awkward cargo.

31. The office accommodation is good. Indeed, the traffic officer can sit at his desk and almost discharge his ship. He is looking out on to the quay and has an overall view of the operations. The shed staff and Customs are in a mezzanine floor and have excellent accommodation. The only criticism here-and is largely a criticism after the event-is that there is a lack of internal communication. We have this problem at Nos 10 and 11 Sheds and this is under investigation. Also, there is no place for the foreman on the warehouse floor to rest his head or to undertake documentation.

32. The local people can see very little reason for the air vents which have been provided in the roof. I understand that they are continuously flapping in the wind. Many think that they will be the cause of a considerable amount of maintenance work and that the ventilation could well have been left to opening and closing the doors. I say this with a certain reserve, because $\mathrm{Mr}$ Peake will have had good reason for the vents.

33. My only other criticism relates to the question of flooding. There is a common downpipe for draining both the roof and the waters from the verandah. Experience has shown that any blockage causes flooding back to the verandah. The floor levels are slightly below verandah level, so that flooding is possible back into the transit areas.

\section{Mr A. J. Harris, Harris and Sutherland}

There are two or three points which the speakers did not mention. We were rather proud of the foundations. The site was littered with large brick piers at very close centres differing from those of our new piers and on a line which was very slightly off our new line. This dictated the method we chose finally for the foundations, which was a large number of small bored piles. We feel particularly happy that they all went down to the proper level, with the exception of about two, without actually hitting any of the brickwork. It was a reasonably inexpensive foundation, too.

35. For the prestressed concrete floors, research in the last ten years has enabled us to design a two-way floor slab of that sort.

36. The other quite minor point about it is that we were given the dimensions of $50 \mathrm{ft} \times 37 \mathrm{ft} 6 \mathrm{in}$, which was an admirable proportion since it enabled us to have full draped cables over the long span and a similar number of straight cables in the short span which was the long dimension of the shed. The major problem with prestressed concrete two way slabs is that if the two dimensions are equal, one needs draped cables in both directions. While this is easy across the width of the building, it is exceedingly difficult in the length of a long building.

Paper published: Proc. Instn civ. Engrs, 1969, 42 (January) 21-37. 
37. My final point concerns the roof. Again, it is pleasant to note advances in science being of some practical use. The barrel vault roof of that sort, a triangulated shell, is attractive. It is easy to build, has visual charm, and is inexpensive. It has, until recently however, been impossible to calculate. While this has never in the past discouraged engineers, these days we do like to do a few sums. This was done in three stages.

38. First, we got Dr Makowski to do an analysis, what I think is called a hand analysis. He then made us a model to confirm it and, finally, a computer program was produced by Stewarts and Lloyds which predicted the deflexions with remarkable exactitude. Now that one can work these things out, I do not see why a lot more people do not use them.

\section{Mr E. Newton. Port of London Authority}

The floor areas and the multistorey layout of the new $M$ Shed were based on a valuable report of the Port of London Authority's planning department. The design office of the engineering department conceived the horizontal and vertical flow of import cargo, the ramp road to the transit shed at first floor level, the wide column grid of $37 \mathrm{ft} 6 \mathrm{in} . \times 50 \mathrm{ft}$ for floor loads of $4 \mathrm{cwt} / \mathrm{sq}$. ft, and the column-free $150 \mathrm{ft}$ span roof with a $30 \mathrm{ft}$ overhang, and also determined the side and roof cladding. The consultants were responsible for all detail design, the production of all contract documents, and for letting and supervising a contract. Their principal structural design contributions were the waffle slab floors in prestressed concrete and the barrel vault roofing in rectangular steel tubes.

40. The floor construction envisaged by the Port of London Authority at the design stage was a flat slab in situ construction. I would like to know whether the Authors think that in view of the evidence with regard to the economy of flat slab construction for bridge decks as well as for suspended floors, this design has the advantage costwise over the straightforward, unexciting flat slab construction.

41. The structural shape selected for the roof by the Consulting Engineers is pleasing and also avoids some of the problems associated with the maintenance of flat or 'low-pitch' roofs. On the other hand it contains a number of valley gutters which are disliked by many engineers, and the cost appears to be somewhat higher than that of other kinds of more conventional roof construction such as the monopitch type of roof currently favoured in the Port of London.

\section{Professor Z. S. Makowski, University of Surrey}

My remarks will be limited to the roof structure. I was fortunate enough to be associated in a small way with the analysis of it and I would like to give some details of an investigation which has been carried out at the University of Surrey on various types of braced barrel vaults.

43. A braced barrel vault is a structure similar in configuration to a shell; however, it is not homogeneous, being an assembly of bars. Six different types of bracing have been investigated and their relative stiffness determined by using small scale models. All models had the same length, width and rise and their bracing members were arranged in such a way that the total weight of material used to construct the models was almost identical in each case. The tests on the various models showed significant differences in behaviour showing that the type of bracing has a fundamental influence upon the strength and load carrying capacity of a braced barrel vault.

44. The tests clearly showed that the type of bracing used by Mr Harris for his structure is the most rigid of the six types investigated. The stresses in members under unsymmetrical loading were much more uniform in this case and the bracing can also resist concentrated loads suspended at various points under the structure.

45. In our analytical investigation of stress distribution in braced barrel vaults 
we used the shell analogy as well as the folded plate analogy. We developed a program for the computer, analysing the structure as a pin connected and also as a rigidly connected skeleton framework, and found that the rigidity of the connexions has a marked influence upon the stress distribution. The rise to span ratio has a fundamental bearing on the buckling behaviour of such structures. We found again that the three way barrel vault gives the greatest rigidity for the minimum amount of material.

46. I was very interested to hear $\mathrm{Mr}$ Shewring's comment regarding the economy of the structure. I have been associated with quite a number of projects involving similar structures and, in many cases, the designers have found that steel barrel vault construction is competitive and in some cases cheaper than the use of a reinforced concrete shell.

47. The roof of the Torroja's Research Institute in Madrid is covered by a series of steel barrel vaults. When Professor Torroja had to build a roof over his own concrete research laboratory in Costillares, he decided to use the three-way steel barrel vault simply because a cost analysis indicated that this structure was cheaper than a reinforced concrete shell. The same conclusions have been reached by one of my French colleagues, Monsieur S. du Chateau, who has built several three-way steel barrel vaults during recent years.

48. Germany and Japan in particular are two countries where several firms have developed prefabricated steel barrel vaults using modular units and special connectors. The erection of these structures, as Mr Harris has noticed, is extremely simple; often they are built without using any scaffolding and this reduces the cost.

\section{Mr R. G. Taylor, Stewarts and Lloyds}

There are many problems associated with this type of roof construction. There appears to be a reasonable possibility of achieving a fairly high rate of production in the workshop, because in principle there are a great many repetitive parts. This would be so, however, only if the job had not to have any camber and no deflexion.

50. Starting on the principle that all the panels can be made identical and can be put side by side and joined together, the roof could be built easily and, when finished, under full loading would probably have a 6 in. dip in the middle.

51. What was probably one of the first mass produced barrel vault roofs built in this country is shown in Fig. 16 . It is a typical $80 \mathrm{ft} \times 40 \mathrm{ft}$ grid. In this case the overall appearance is rather similar to the Port of London Authority job, but when looked at carefully it is seen that alternate longitudinal members are formed by two tubes side by side. This particular barrel is prefabricated into mats in long lengths with one central tube up the middle and a tube at each side. These are cranked like a piece of flat paper folded up the centre and at site when the edges are brought together, temporary connexions are put in and the joints eventually site welded to form a barrel type structure.

52. This was not designed on a computer but on the simple assumption that the roof was a semi-circular beam spanning longitudinally - as a beam with the tension member at eaves level in the ordinary way -but each tubular longitudinal member sharing a part of the compressive load. It was put up almost as the load bearing structure, as the reinforcement, so to speak, of what was eventually a shell clad in non-loadbearing concrete. Fig. 16 shows the light mesh and rod infill on to which light concrete was sprayed.

53. In this case the panels were made identical and the resulting structure had a very slight deflexion in the middle of the roof, roughly 1 in. on $80 \mathrm{ft}$ which was not too bad for something which was completely prefabricated. In those days we did not have computer facilities and, therefore, this was the only easy way in which that sort of roof could be designed.

54. Fig. 17 shows what is, as far as I know, the only other existing barrel vault 


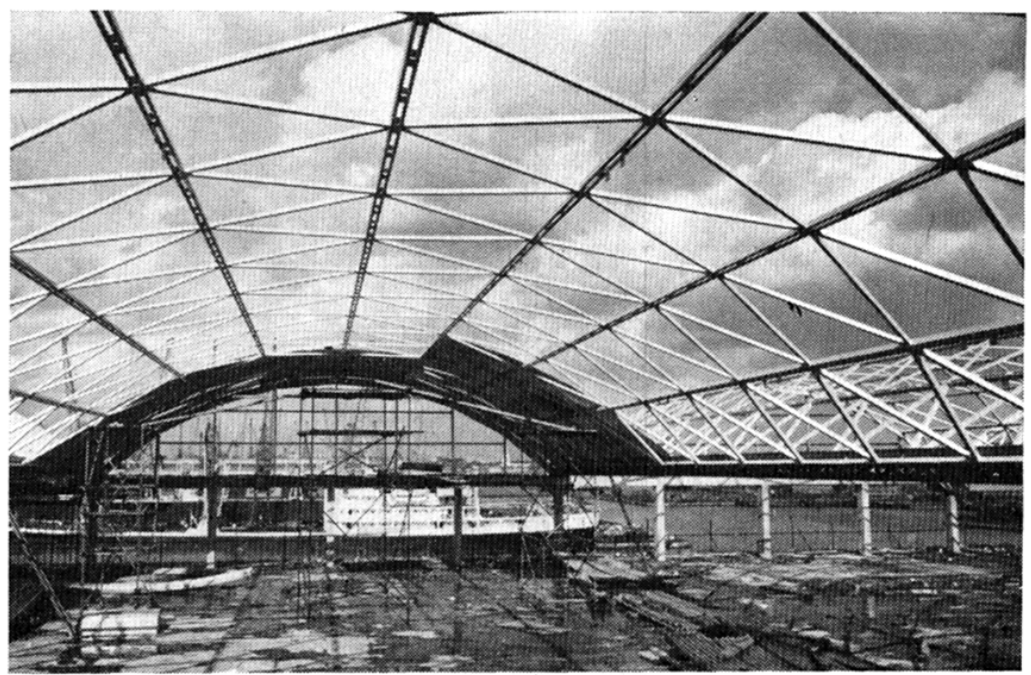

Fig. 18. The width of the prefabricated panels is roughly $10 \mathrm{ft}$ which meant they could not be supplied in double width mats

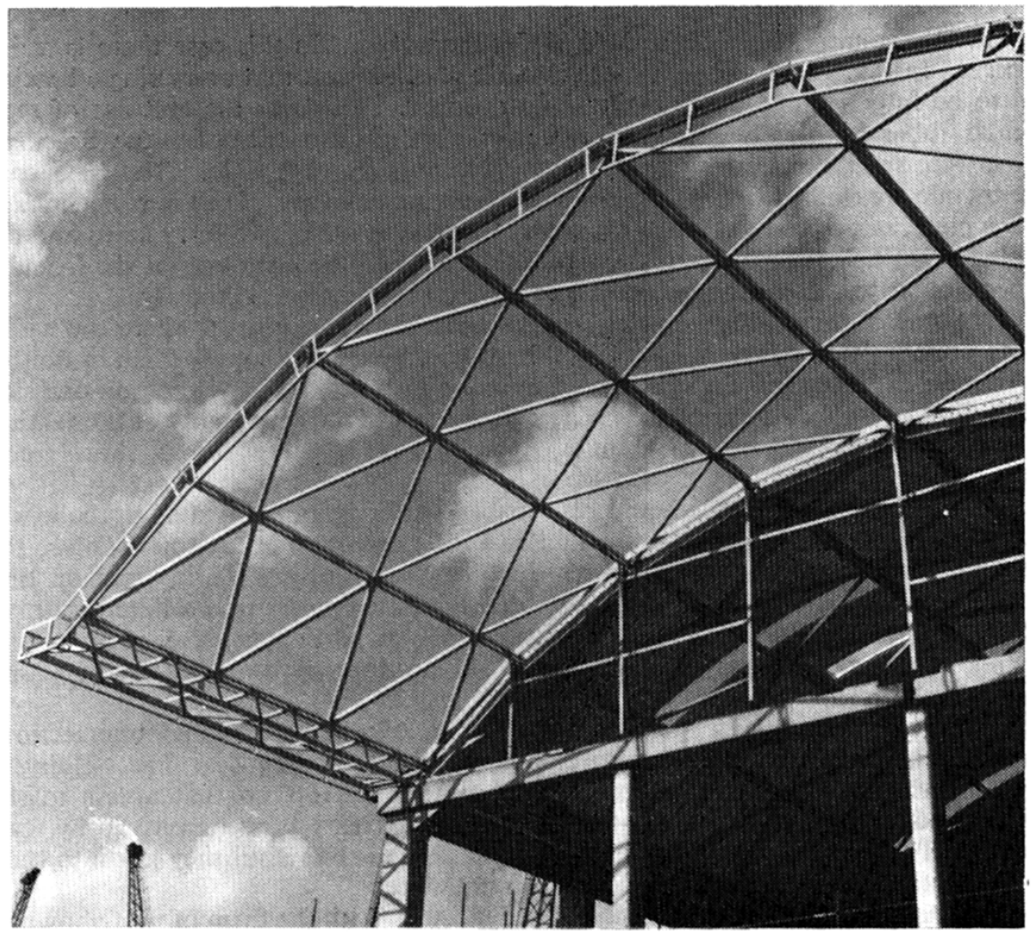

Fig. 19. The welding is partly overhead, with cleats underneath as well as on top, so that access to the welders had to be given throughout the job Downloaded by [] on [26/04/23]. Copyright @ ICE Publishing, all rights reserved. 


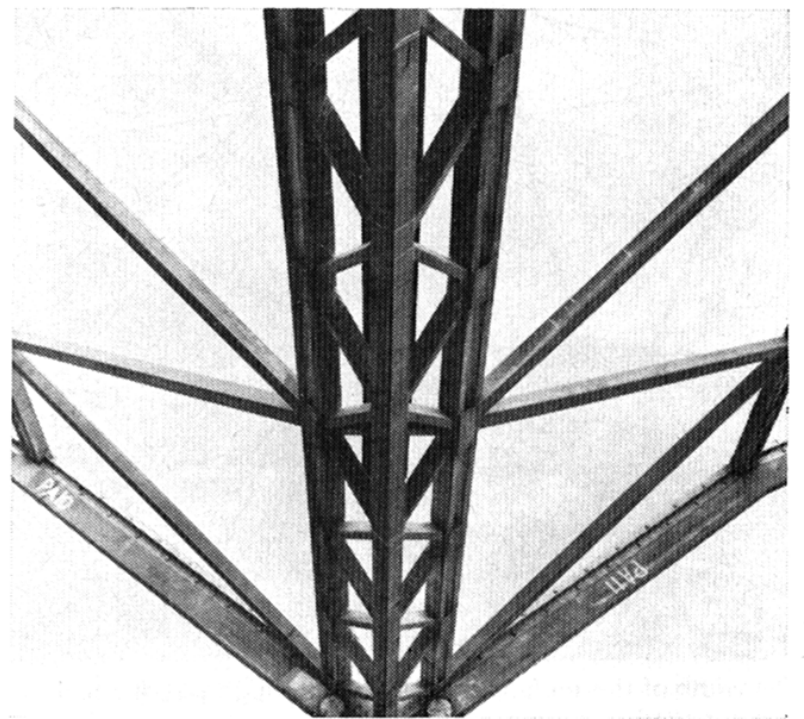

Fig. 20. The valley beam

roof in this country, built on a dock at Southampton. In this case there is a difference. In Fig. 16 all members were circular which meant that every single bracing had to be fully saddled on to every main member. This was the first use of rectangular tubes for the longitudinal members with circular tubes for the bracings. These were small barrel vault roofs about $32 \mathrm{ft}$ long by $16 \mathrm{ft}$ wide. The 16 barrels side by side are clad with timber so the steel is now covered in. They were each made in one piece, nested one on top of the other, shipped to site in two lorry loads and the whole lot put up extremely quickly. One feature, the little cantilever at the front, is rather similar to the much greater one at the Port of London Authority.

55. Some of the problems which can arise are shown in Fig. 18 where the width of the prefabricated panels is roughly $10 \mathrm{ft}$ so that we cannot supply them in double width mats as in the first illustration. The main members have welding on one side in the shop and none on the other. There is, therefore, the probability of fabrication distortion and a problem to overcome. The final result, nevertheless, shows good lines.

56. The panels in Fig. 17 should be visualized as being prefabricated in the workshop; looking along the roof there would be a different upset at the top owing to the deflexion than at a point lower down. In other words, every single point on that barrel has a different deflexion and, therefore, has to be preset to a different camber in the shop. Each panel had to be fabricated with its particular preset in an adjustable jig to try to get mass production and yet produce the finished job to within reasonable tolerance.

57. The resulting clean line is pleasing; Fig. 19 shows diagonal intersections reinforced by these very bold lines giving good visual appearance. The welding is partly overhead, with cleats underneath as well as on top, so that access to the welders had to be given throughout the whole job. This was accomplished by scaffolding. The first bay and a half took a good deal of time until they got into their swing but then they did the last five bays in nine weeks.

58. The valley beam is shown in part in Fig. 20. With the form of roof shown in 
Fig. 16 it would be the main tension member. It often consisted of a single large joist which might span as much as $80 \mathrm{ft}$ partly supported in itself by the inherent stiffness of the arch but acting purely as a tension member. Again, there was the problem of deflexion in the valleys between barrels.

59. The valley girder, showing triangulated cross-section with the base uppermost, is illustrated in Fig. 20. This permits access along the valley and gives a wide gutter for rainwater disposal. The connexion of the prefabricated lattice girders to the valley girders by the cleats shown entails a fair amount of site welding.

60. I wish to make one final observation from the consultant's point of view. One of the problems on this type of work is to get access, because normally we like to build barrel vaults like this complete on the ground and lift them up in one piece. In this case the job was multi-storey so it could not be done, but owing to close collaboration between the consultant and the main contractor we got the Port of London Authority to lift our crane on to the floor.

\section{Mr F. A. Page, Port of London Authority}

Very little has been said about foundations, and I note that the Authors say that the 22 in. piles took 80 ton loads. This is fairly low. Piles of this diameter would be capable of taking a 120 ton load, but this depends upon having fairly dense gravel on which to found.

62. It is mentioned in the Paper that the gravel was somewhat loose in parts, and this might have caused some of the trouble. Smaller diameter piles may have driven through the ballast into the stratum below, the extra length being more expensive overall. There is no mention of this, and it would be interesting to know if this was the case. It might explain why the rather lighter load had been used for the piling.

63. My second point, which has already been partly mentioned, concerns the price of the roof. I would not expect a precast concrete roof for a transit shed to be a viable economic proposition, and it is no surprise that the lattice steel frame used was considerably cheaper than the concrete roof. However, I understand that apart from the precast concrete design, comparison had also been made with a normal steel frame of truss design of some kind or another and that this also was rather more expensive than the form finally adopted. I find this a little difficult to understand, and information on this second comparison might be useful.

64. From the items given at the end of the Paper the price per sq. $\mathrm{ft}$ for the roof construction adopted, including the canopy, appears to be about $£ 1.4$ per sq. $\mathrm{ft}$. For shed roofs built with a traditional type of long span steel truss, it is possible to get the steelwork for about $10-11 s$ per sq. ft and the cladding about $6 s 6 d$, giving a total cost of $£ 0.8-£ 0.9$ per sq. $\mathrm{ft}$.

65. Mr Shewring has said that the price for the roof finally used worked out a little more expensive than was expected and this possibly accounts for some of the difference, but it seems rather costly. It would be useful if details could be given of the comparison made between this barrel vault type of roof and the more traditional roof truss.

\section{Mr R. A. Smart, formerly Holloway Brothers}

In the floor slabs an enormous amount of stressing was required to make the slabs work.

67. The longitudinal cables were probably the longest stressed at that time, being in the order of $530 \mathrm{ft}$, and they presented considerable problems. The problems in the transverse cables were known at the time of design, i.e., they are the normal parabolic type and, hence, one can calculate the friction losses.

68. In constructing the longitudinal cables, it was decided to incorporate the top cables in a duct running along the top of the slab, the lower cables being in a sheath. In theory, a long straight duct offers no frictional resistance to the cable, but, in 
practice, it was found that there was considerable friction along the length of the cable and the expected extensions were not at all times achieved.

69. If a correct load gauge reading for the stressed cable is obtained, but the theoretical extension is not, does this mean that the permissible live load should be reduced or are the loadings of 4 and $3 \mathrm{cwt}$ for the first and second floors respectively still acceptable?

Mr M. J. Puller, Foundation and Structural Services Ltd

After hearing from Professor Makowski I feel very hesitant in agreeing with the previous speaker on the benefits of a monopitch roof, which I advocate for financial reasons. Perhaps the cost of the frame is rather high because of the higher material cost of the RHS section and the fabrication, even though the weight per sq. $\mathrm{ft}$ is fairly low.

71. With regard to the aluminium sheeting I would be interested to know from the Authors whether any movement differentially between steel and aluminium has proved a difficulty and how it was dealt with.

72. The question of condensation is of interest when building warehouses for perishable goods. I note that in previous Port of London Authority monopitch warehouses a considerable amount of smoke ventilation has been provided. Presumably these alleviate the condensation together with a fair amount of glazing which has been provided. I should be interested to hear from the Authors their attitude towards condensation with aluminium sheeting.

73. Were sealants necessary for use with the aluminium sheeting in the fairly low pitch near the highest part of the barrel vault and, if so, what life could they be expected to have?

Mr I. W. Menzies, Charles Weiss and Partners

Apart from Mr Smart's comments, very little has been said about the actual construction. Let us start with the piled foundations.

75. Several speakers have referred to the fact that the existing site conditions were hardly ideal for piling in view of the proliferation of existing brick walls, brick piers, bits of rafts, old concrete and other underground obstructions. Therefore, a detailed piling layout was not prepared for the Contractor to work to.

76. From the column layout, the optimum size pile cap to accommodate the optimum number of piles for the column was set out. The Contractor then excavated approximately $3 \mathrm{ft}-3 \mathrm{ft} 6$ in. below the existing old shed floor level. This proved sufficient in all cases to locate the tops of the existing obstructions. The Resident Engineer then designed a pile group symmetrical about the column, at the same time avoiding the piers and bricks. Every column has an individually designed pile group and pile cap underneath it.

77. To avoid the possibility of building up pressure behind the existing dock wall, which is $100-110$ years old, it was specified initially that the line of piles under the columns on the north side of the shed, adjacent to the quay wall, should be driven in advance of any piles within the shed. This meant that at the peak of the substructure contract there were four rigs in echelon with that on the quayside leading by about two grid lines. At the peak we were driving 20-40 piles per day.

78. The precast concrete lower hinges solved many problems, but presented certain constructional difficulties. The first was providing an adequately smooth, level base on top of a pile cap on which to place the lower hinge. The Contractor tried various experiments-not on an actual pile cap-with top shutters and retardants, but the only really acceptable solution was found to be a template at preset levels with a steel float on top and grinding off any high points before placing the actual hinge.

79. The upper hinges were cast in situ. The amount of reinforcement, as illustrated in the Paper, was such that it was physically impossible to concrete the column from the top with the hinge reinforcement in position. 
80. The original design of the hinge steel was slightly modified to enable the column to be concreted to the underside of the hinge with the hinge reinforcement not positioned. When the concrete reached underside of hinge level, the top cage was lowered into position, suspended from the top of the shutters and then, changing to the $8000 \mathrm{lb} / \mathrm{sq}$. in. concrete mix to which $\mathrm{Mr}$ Shewring referred, the concreting was continued to ensure that column and hinge were monolithic.

81. The formwork for the suspended floors is something on which the Contractor should be congratulated. The fibreglass moulds did not have the normal bottom lip as in the proprietary types.

82. The transverse ribs were supported on long timber runners; the longitudinal ribs on $4 \mathrm{ft}$ long timber runners which were demountable. The coffers fitted within the square, projecting down below the soffit of the actual rib, to which they were bolted by the shaped timbers running alongside the soffit shutter. This meant that the coffers could be stripped within 48 hours and reused. Therefore, with approximately 350 moulds the total 10000 coffers could be constructed. It also enabled the bearers to be reused after stressing in the transverse direction, (Fig. 8).

83. The only snag in the earlier stages was that the transverse bearers set directly into U-heads on conventional screw props. This meant that the scaffolder who was erecting the staging $20 \mathrm{ft}$ up had to be accurate to within an inch. This is a little beyond the tolerances to which scaffolding foremen normally like to work. I think that had additional bearers been introduced to allow a certain latitude in the position of the U-heads, this would have speeded erection considerably and saved a certain amount of labour contention.

84. Mr Smart referred to the longitudinal cables and the grooves introduced at the Contractor's request. In the original design there were two sheaths, one above the other. With hindsight, I think that this groove was a mistake. It was almost impossible to impress on the workmen the dangers of wandering about on top of a slab with $12 / 0 \cdot 315$ cables fully stressed lying in a relatively unprotected position.

85. The threading of the cable in the lower sheath also presented a difficulty. A bullet consisting of a $\frac{1}{2}$ in. bolt with two steel washers at each end and a fibre washer between was inserted into one end of the sheath with the draw wire attached. A blow pipe was entered into the sheath behind, and the bullet shot through the $530 \mathrm{ft}$ duct.

86. I understand that on the valley the calculated deflexion was 6 in. under full load. The measured deflexion after removing the false work and before any cladding and, therefore, under approximately one-quarter of the design load, was $1 \frac{1}{2}$ in. I leave others more qualified than I to decide whether that was coincidence, good workmanship, or good design.

\section{Mr P. J. Rendle, Temporary Works Department, John Laing and Son, Ltd}

The Authors have described the sequence of construction and stressing of the coffer slabs. The propping of the lower slab and the upper slab from the lower slab on the column lines was with tubular scaffold birdcage of 30 standards braced horizontally and diagonally together into a tower.

88. I understand that the scaffold propping under the first floor appeared to be overloaded when this slab was stressed transversely. All the standards in the scaffold towers had bowed laterally approximately 3 in., all the standards in each tower moving in the same direction. The scaffold towers between the first and second floors showed the same unhappy symptoms of overloading when the second floor was stressed transversely. When the longitudinal stressing operations were completed the slab soffits had lifted approximately $\frac{1}{2}$ in. off the supporting scaffold leaving these towers in their deformed position.

89. To assist contractors on future contracts, could the Authors state what loads were applied to the scaffold towers to cause the apparent overloading?

90. Were these loads and movement of the slab anticipated before the structure was built? 
91. Do the Authors consider that attention should be drawn at estimate stage to any abnormal loads and movements likely to affect the design of falsework?

\section{F. G. Peake and R. A. Shewring}

We would like to thank the contributors to the discussion for the various points raised.

93. Mr Gabony, in the role of the customer, has raised the question of the roof ventilators. The side flaps in these remain in the open position to provide ventilation when the shed is shut down. They are on a fusible link and thus close in the event of fire, simultaneously the top vents spring open giving ventilation of smoke through the full throat opening of $16 \mathrm{sq}$. $\mathrm{ft}$.

94. The ingress of water from the balconies into the shed floors under the doors has now been prevented by means of drainage channels under the sliding doors.

95. We would thank Mr Menzies, who was formally the Resident Engineer, for describing some of the constructional problems. We would agree that, while substitution of an open groove for the upper longitudinal cable sheath produced a cost saving, it was not only a possible safety hazard, but it prevented the power floated topping being laid and finished until all these cables had been stressed and grouted. If the original sheath had been kept within the slab, the finishing operations to the floors would have been much quicker.

96. We agree with $\mathbf{M r}$ Smart that the frictional resistance of the longitudinal duct was greater than anticipated which we consider accounted for the differences between the load gauge readings and the extensions. This resistance, we feel, was probably due to a greater 'wobble' factor for the duct than was estimated for in the design. The result is to slightly reduce the cracking load, and its overall effect upon the permissible live loads is negligible.

97. Replying to Mr Newton we would say that the in situ reinforced concrete flat slab originally envisaged by the PLA included dropped panels and mushroom column heads. The prestressed solution adopted, is a true flat slab and produced an estimated cost saving of about $15 \%$, when compared with the original reinforced concrete flat slab. This saving on an item which exceeded a third of the total cost of the job, we feel is a major contribution in achieving a cost of $33 \mathrm{~s} / \mathrm{sq}$. $\mathrm{ft}$ for the floor slabs. The incorporation of waffles produced considerable economy in the dead weight of the structure and hence on foundation costs and also on shuttering due to the number of uses for each waffle shutter.

98. Mr Page was quite correct in thinking that the figure of 80 tons working load for the piles was due to the loose gravel ballast in which they were founded and particularly as this stratum was thin over the central area of the site. SPT values of 20-30 in this gravel were obtained during the site investigation. It was hoped that the driving might compact the gravel, but this only occurred to a limited extent.

99. The four preliminary test piles were driven and attempts made to load these to three times working load to see whether this could be raised from 80 tons. These piles failed at $140,240,190,220$ tons respectively, so this working load was kept. The results of these tests are available in the piling records of the ICE.

100. The cost of the roof structure as Mr Page remarks, is higher than the traditional port single storey transit shed and in comparing the figures he has quoted, the following should be noted.

101. The roof was erected some $60 \mathrm{ft}$ above ground level, the whole of the steelwork was galvanized and as this was a nominated subcontract the figures quoted include the cost of the Main Contractor's attendance, profit, etc. From the figures quoted in Appendix 2, the cost of steelwork was $13 \mathrm{~s} 6 \mathrm{~d} / \mathrm{sq}$. ft of covered area (including canopy). In our opinion this compares favourably with figures given by $\mathrm{Mr}$ Page of $12 s 1 d$ and $12 s$ 6d for similar span sheds at Tilbury ${ }^{1}$ and by Mr Newton of $11 s$ for the new ' $P$ ' berth shed at Millwall Docks, ${ }^{2}$ all these sheds being single storey. The cost of roof cladding was $7 s 0 d$. The remaining $7 s 6 d$ per sq. $\mathrm{ft}$ (making a total of 
$£ 1.4 /$ sq. $\mathrm{ft}$ ) covers the cost of roof vents, lights, gutters and downpipes to ground level, including balcony drainage; also fire protection to the roof steelwork adjacent to the warehouse division walls.

102. In answer to Mr Puller there are no problems of condensation with aluminium sheeting as this reacts so rapidly to changing atmospheric conditions. Our experience with asbestos cement sheeting is different as this tends to cause condensation on supporting steelwork particularly boom members of steel trusses, where these are of large enclosed box or circular cross section.

103. Any differential movement between steelwork and aluminium sheeting is absorbed by the timber blocks which lift the sheeting just clear of the steel members.

104. All end laps in the sheeting were sealed with 'Duralec' Joint Compound No. 4626 , which according to the manufacturers has a life of approximately 20 years. Sheets in lengths of 20 and $30 \mathrm{ft}$ avoid lapping near the crown of the barrels.

105. We agree with Mr Rendle that any special characteristics of a structure requiring particular attention during construction should be stated at the tendering stage. On this Contract the method of construction proposed in the specification included the estimated movements of the structure after stressing and this method was closely followed by the Contractor.

106. Bowing of some of the scaffolding towers after transverse stressing occurred due to a lack of sufficient bracing standards. As far as we are aware the application of the uniform longitudinal prestress did not in fact, cause the slabs to lift off the soffit shuttering.

\section{References}

1. Smearden R. J. F. et al. Engineering works at Tilbury Docks 1963-67. Proc. Instn civ. Engrs, 1967, 38 (October) 177.

2. Newton E. Transit shed for PLA. Tubular Structures 9 (Stewarts and Lloyds Ltd), November, 1967. 